\title{
OPEN Author Correction: Apparent Power Law Scaling of Variable Range Hopping Conduction in Carbonized Polymer Nanofibers
}

\section{Kyung Ho Kim, Samuel Lara-Avila, Hojin Kang, Hans He, Johnas Eklöf, Sung Ju Hong, Min Park, Kasper Moth-Poulsen, Satoshi Matsushita, Kazuo Akagi, Sergey Kubatkin \& Yung Woo Park}

Correction to: Scientific Reports https://doi.org/10.1038/srep37783, published online 25 November 2016

This Article contains a typographical error in Equation 1.

$$
I=I_{0} T^{\propto+1} \sinh \left(\frac{\gamma e V}{k_{B} T}\right)\left|\Gamma\left(\frac{1+\beta}{2}+\frac{i \gamma e V}{2 \pi k_{B} T}\right)\right|^{2}
$$

should read:

$$
I=I_{0} T^{\propto+1} \sinh \left(\frac{\gamma e V}{2 k_{B} T}\right)\left|\Gamma\left(\frac{1+\beta}{2}+\frac{i \gamma e V}{2 \pi k_{B} T}\right)\right|^{2}
$$

(c) (i) Open Access This article is licensed under a Creative Commons Attribution 4.0 International Ly License, which permits use, sharing, adaptation, distribution and reproduction in any medium or format, as long as you give appropriate credit to the original author(s) and the source, provide a link to the Creative Commons license, and indicate if changes were made. The images or other third party material in this article are included in the article's Creative Commons license, unless indicated otherwise in a credit line to the material. If material is not included in the article's Creative Commons license and your intended use is not permitted by statutory regulation or exceeds the permitted use, you will need to obtain permission directly from the copyright holder. To view a copy of this license, visit http://creativecommons.org/licenses/by/4.0/.

(c) The Author(s) 2020 